\title{
Study on the impact of coastal land use change on environment based on remote sensing data
}

\author{
LIU Yong ${ }^{1, \mathrm{a}}$ Yunlin Chen ${ }^{1, \mathrm{~b}}$ \\ ${ }^{1}$ College of water conservancy engineering,Zhejiang Tongji Vocational College of Science and Technology, Hangzhou, \\ Zhejiang, China
}

\begin{abstract}
The coastal zone is the bridge between the ocean and the mainland, the junction of the two ecosystems, the focus of the economic development of coastal cities and the gathering place of ports. Remote sensing technology uses the detector to receive the electromagnetic wave from the target object. After processing the information, it can distinguish the attributes of the target object. It is widely used in marine development, aerospace understanding, resource exploration and other fields.In this paper, the coastal zone of Shangyu Economic Development Zone on the south coast of Hangzhou Bay is taken as the research area. Using multi-source remote sensing data, information extraction, change monitoring and analysis are carried out from the perspective of marine and land ecosystems, and the impact of coastal development on the coastal zone is discussed. The main conclusions are as follows:

(a)Using visual interpretation method, it is found that the coastline of the study area changes obviously, and the decrease trend is below the total coastline length; Fractal dimension index is used to characterize the natural condition of coastline. The total coastline length, natural coastline and artificial coastline all increase, which means that the amount of beach sediment deposition and the degree of artificial intervention have increased in this stage.

(b)The object-oriented method is used to extract the land use classification of the coastal zone in the study area. Cultivated land is the main land type in the study area, and the impervious surface is the fastest growing. The degree of artificial development of the whole study area is gradually increasing, and the coastal beach area is greatly reduced, and the impervious surface area is greatly increased. Wetland and impervious surface are the two most dramatic changes in the study period. Wetland is mainly transformed into other surface features, while impervious surface is mainly transformed into other surface features.
\end{abstract}

\section{Introduction}

\subsection{Research background}

Coastal zone is the junction of hydrosphere, atmosphere, lithosphere, biosphere and human life circle. It is the contact zone between terrestrial ecosystem and marine ecosystem. It is the base of human understanding of land and ocean. It is usually divided into coast, intertidal zone and underwater slope. As the junction of various open ecosystems, the coastal zone has the characteristics of complex, marginal and active because of its unique geographical location and landscape ecological conditions, which shows that the exchange and circulation of material and energy are very frequent. The coastal zone is located in the lowest part of the mainland. With more and more people transferring their living and development to the coastal area, whether for the purpose of urban development or comprehensive industrial development, industrial waste, agricultural waste, domestic waste and other pollutants on land need to pass through the coastal zone before entering the ocean. This makes the coastal ecosystem extremely

aemail: tjxy@zjtongji.edu.cn, bemail:531545113@qq.com 
fragile and vulnerable to human activities. From the perspective of coastal zone evolution, the comprehensive human activities and geo ecological processes can reveal the corresponding characteristics of its spatial form to natural and human factors. Studying the influence of coastal area development on coastal zone can not only monitor the environmental pollution around the coastal zone, but also detect whether the environmental protection measures taken by human beings in the development and utilization are effective.

Hangzhou Bay is located in the middle of the west coast of the Pacific Ocean and the northeast of Zhejiang Province in the Yangtze River Delta. It is the largest Bay in the southeast coast of China, The geographical location is $120.95^{\circ} \sim 122.07^{\circ} \mathrm{E}$, $29.92^{\circ} \sim 30.86^{\circ} \mathrm{N}$, It is a typical area of coastal zone research in China ${ }^{[1]}$.

\subsection{Research content}

Taking Shangyu Economic Development Zone (north area) in Hangzhou Bay as the research area, the coastline and surface cover were extracted from the Landsat data in 1993, 1998, 2003, 2008, 2013 and 2018. The measured data and environmental 1a HSII hyperspectral data were combined with the multi-source remote sensing data to conduct a long time series study from the perspective of temporal and spatial changes. This paper reports from the following aspects:

(a)The Landsat and environmental 1A HSI data of the study area were obtained and preprocessed, including radiometric calibration, atmospheric correction and study area clipping.

(b)he coastline of many years is extracted by visual method, and the land cover of many years is extracted by object-oriented method.

\section{Overview of the study area}

Hangzhou Bay Shangyu Economic Development Zone (hereinafter referred to as the Economic Development Zone) is located in Shaoxing City, Zhejiang Province. The research scope of this project includes Yuecheng district and Shangyu district, The sea area is bounded by the administrative region, and the land area extends to the right administrative region of Shangyu from the East-West section of Cao'e River in the 2018 Landsat Image. The left and right sides are the boundaries of Shangyu Administrative Region. The total area of this study area is 439.21 square kilometers. The study area is the area with the fastest siltation in the South Bank of Hangzhou Bay, so most of the area is reclamation area, including economic development area, which is also formed by years of reclamation.

\section{Data acquisition and preprocessing}

\subsection{Data acquisition}

3.1.1.Landsat data.Landsat series of land satellites are jointly managed by NASA and USGS, which are a series of earth observation satellite systems used to explore the earth's resources and environment. The Landsat data used this time is obtained from the USGS official website ( http://glovis.usgs.gov/ ), including two kinds of data: landsat5 TM and landsat8 oli.

3.1.2.HSI hyperspectral data.HJ-1A, a small satellite constellation used in the detection and prediction of environment and disaster reduction in China, was successfully launched in 2008. The HSII sensor carried by HJ-1A has 115 bands, with a wavelength range of 0.459 to $0.956 \mu \mathrm{m}$. The average spectral resolution can be as high as $4.32 \mathrm{mn}$. Although the spectral coverage is narrower than other multispectral data or high resolution data, the spectral resolution has been significantly improved, and its sensitivity to ground objects is better than other data.

\section{Spatiotemporal study on land use change of coastline and coastal zone}

The change of coastline is influenced by many factors, including natural action and artificial action. The natural processes include: the transformation of coastline caused by geological processes, the deposition of sediment carried by rivers, the erosion of coastline caused by sea level changes, extreme weather caused by weather changes, and the sharp change of coastline caused by disasters; Human activities include the construction of artificial dams, reclamation, sand mining and other activities. According to the research results of the world coastline and China coastline, the Yangtze River Delta Area [2] [3] [4] [5] including Shanghai is an area with rapid urban expansion, significant expansion of human activities to coastal areas, and rapid coastline change. Reclamation occurs in almost all coastline areas in China. 


\subsection{Research methods}

4.1.1.Coastline Extraction and attribute assignment.There are many definitions of coastline. In this study, we use the water body index method and visual interpretation method to extract the coastline of the study area. The water body index was calculated by comparing Normalized Difference Water Index (NDWI) and Modified Normalized Difference Water Index (MNDWI), After two methods, MNDWI was determined. The formulas $(1,2)$ of the two methods are as follows: $N D W I=($ Green $-N I R) /($ Green $+N I R)$ $M N D W I=($ Green $-M I R) /($ Green $+M I R)$

Green is the green band, NIR is the near infrared band, and Mir is the mid infrared band.

In the analysis of water index calculation results, it is found that the spectral characteristics of soil and buildings are similar to that of water in the green and near-infrared bands, so it is easy to confuse water with buildings and soil by NDWI, while the reflectivity of buildings increases sharply from near infrared to mid infrared, and the reflectivity of water near mid infrared continues to decrease, MNDWI greatly reduces the interference of soil and buildings, and reduces the background noise.

According to visual judgment, MNDWI effect is better, as shown in Figure 1. 1A is the NDWI schematic diagram of the study area in 2018, and $1 \mathrm{~B}$ is the MNDWI schematic diagram of the study area in 2018. The deeper the color show the higher the water content. It is obvious that the water differentiation of the left figure is higher, that is, MNDWI can achieve better water boundary extraction effect; The right picture can distinguish the water quality of different waters of Cao'e River and Qiantang River. MNDWI index is used to extract the water boundary.
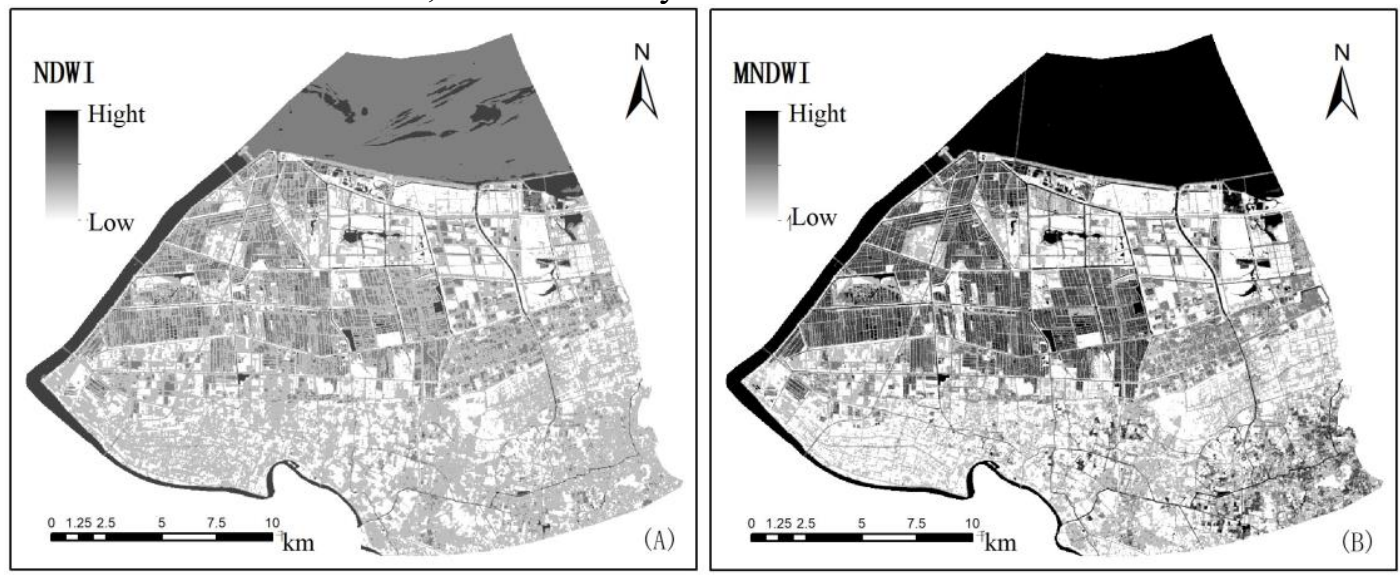

Figure 1 comparison of NDWI / MNDWI

Combining MNDWI with the original remote sensing image, the part with MNDWI greater than 0 is visually interpreted by human-computer interaction, and the water near the inland part of the shore is removed. Then the vector water line is drawn in ArcGIS, and the error is controlled within one pixel. Finally, the natural coastline and artificial coastline are classified according to the attribute categories of coastline, The natural shoreline in the study area is mainly muddy shoreline, and the artificial shoreline is mainly sluice, dike and protective shoreline.

4.1.2 Land use extraction in coastal zone.Land use / Cover Change (LUCC) is one of the core issues in the study of global environmental change. Coastal zone is a transitional zone between ocean and land, a typical ecotone, and an area with high intensity of human activities. Coastal land use research has become a hot issue of multidisciplinary research. Due to the excessive characteristics of coastal zone and frequent human activities, land use types are complex and diverse, and land use changes frequently.

The object-oriented classification method takes the multi-scale object composed of multiple adjacent pixels as the minimum classification unit, and uses the geometric information, semantic information, texture information and topological relationship between objects to extract the surface feature information. This method uses spectral, geometric and structural information for multi-scale segmentation of images to obtain image objects, effectively avoiding the generation of broken plates. It makes full use of the spectral, shape, texture and spatial relationship features of ground objects to reduce the influence of "foreign objects with the same spectrum" and "foreign objects with the same spectrum" on classification and the mutual influence between spectra to a certain extent, which can effectively avoid "salt and pepper phenomenon", Finally, it can output high-precision classification results or vectors. In this project, the 
object-oriented classification method is used to extract four kinds of features in the coastal zone of economic development zone. The main steps include multi-scale segmentation, classification hierarchy construction, classification rules determination, training sample selection and information extraction.

Compared with the global land cover products obtained by the Institute of remote sensing of Chinese Academy of Sciences Based on the random forest classification method, the extracted results are more consistent with the actual situation of the study area.

\subsection{Coastline extraction results and analysis}

4.2.1.Analysis of shoreline length change. Six periods of shoreline from 1993 to 2018 after visual extraction. The coastline of 2018, 2013 and 2008 is drawn from Caoejiang sluice, and the coastline is drawn from west to east from the same location in 2003, 1998 and 1993. The discontinuity of the coastline in 2003 is due to the Beach expansion caused by sediment deposition, crossing the administrative boundary of Shangyu district. In order to make the interannual changes have contrast, we cut off the part beyond the region. Since 2008, the coastal water line has been gradually stabilized, because the reclamation area has been basically completed, and the northern coast has built a dike, forming a stable coastline.

According to the distinction between artificial shoreline and natural shoreline, the length change of shoreline in the study area over the years was counted through artificial judgment. From 1993 to 2018 , the total length of shoreline is $62971.17 \mathrm{~m}$, $40077.053 \mathrm{~m}, \quad 60013.734 \mathrm{~m}, \quad 46977.863 \mathrm{~m}$, $18723.718 \mathrm{~m}$ and $20989.618 \mathrm{~m}$; The natural shoreline length is $47514.598 \mathrm{~m}, 33004.065 \mathrm{~m}, 43527.707 \mathrm{~m}$, $20506.756 \mathrm{~m}, 7530.854 \mathrm{~m}$ and $0 \mathrm{~m}$ respectively, accounting for $75.45 \%, 82.35 \%, 72.53 \%, 43.65 \%$, $40.22 \%$ and $0 \%$ of the total shoreline length; The artificial shoreline length is $15456.572 \mathrm{~m}$, $7072.988 \mathrm{~m}, \quad 16486.027 \mathrm{~m}, \quad 26471.107 \mathrm{~m}$, $11192.864 \mathrm{~m}$ and $20989.618 \mathrm{~m}$, accounting for $24.55 \%, 17.65 \%, 27.47 \%, 56.35 \%, 59.78 \%$ and $100 \%$ of the total shoreline length.

During the 20 years from 1993 to 2018, the length of natural shoreline only increased from 1998 to 2003, and the rest of the time decreased until all the shorelines in the study area became artificial. From 1993 to 1998 , it decreased by 14510.533 m, decreased by $30.54 \%$; from 1998 to 2003 , it increased by $10523.624 \mathrm{~m}$, increased by $31.89 \%$; from 2003 to 2008 , it decreased by $23020.951 \mathrm{~m}$, decreased by $52.89 \%$, From 2008 to 2013, it decreased by $12975.902 \mathrm{~m}$, down $63.28 \%$, from 2013 to 2018 , by $7530.854 \mathrm{~m}$, down $100 \%$, with a total decrease of $47514.6 \mathrm{~m}$, down $100 \%$. The change range in 2008 was the largest, and the change speed in 2013 was the fastest.

The length of man-made shoreline showed a fluctuating upward trend, which decreased from 2008 to 2013, and increased in the rest of the time. It decreased by $8383.584 \mathrm{~m}$ from 1993 to 1998 , decreased by $54.24 \%$, increased by $9413.039 \mathrm{~m}$ from 1998 to 2003 , increased by $133.08 \%$, increased by $9985.08 \mathrm{~m}$ from 2003 to 2008 , increased by $60.57 \%$, and decreased by $15278.24 \mathrm{~m}$ from 2008 to 2013 , decreased by $57.72 \%$, From 2013 to 2018 , it increased by $9796.754 \mathrm{~m}$, increased by $87.53 \%$, and the total increase was $35.80 \%$. The change range was the largest in 2013, and the change speed was the fastest in 2003.

From 1993 to $2018, \quad 66.67 \%$ coastline disappeared, from 1993 to 1998 decreased by $36.36 \%$, from 1998 to 2003 increased by $49.75 \%$, from 2003 to 2008 decreased by $21.72 \%$, from 2008 to 2013 decreased by $60.14 \%$, and from 2013 to 2018 increased by $12.10 \%$. The main reason for the decline of the total shoreline length is the reclamation and development of the beach under the coastal planning, which makes the original natural form of the curved shoreline into a regular boundary.

4.2.2.Analysis of shoreline morphological change. In this study, the grid method is used to calculate the fractal dimension of the coastline of the Economic Development Zone.Grid method is to cover coastline with square grids with different side lengths, count the information of non overlapping linear grids, get different number of grids, and finally calculate the fractal dimension.

ArcGIS software is used to cover the coastline of the target economic development zone with grid. The square length of the grid is taken as the integral multiple of the spatial resolution of the image: $30 \mathrm{~m}$, $60 \mathrm{~m}, 90 \mathrm{~m}, 120 \mathrm{~m}, 150 \mathrm{~m}, 180 \mathrm{~m}, 210 \mathrm{~m}, 240 \mathrm{~m}$. Through the grid method analysis, different grid numbers are obtained. According to the logarithmic relationship of the data over the years, the obtained values are linearly fitted to obtain the linear equation.

The range of coastline fractal dimension is $1<\mathrm{d}$ $<2$, and the larger the $\mathrm{D}$ is, the more tortuous and complex the coastline is. The calculated coastline fractal dimension of the economic development zone is 1.01803 in $1993,1.03973$ in $1998,1.0133$ in 2003, 1.02861 in 2008, 1.03322 in 2013 and 1.01119 in 18, which is consistent with the conclusion of theoretical analysis, The fractal 
dimension is the maximum, while the minimum is in 2018 when the natural coastline accounts for the lowest proportion. According to the numerical analysis of fractal dimension, it increased by 0.0217 from 1993 to 1998, decreased by 0.0264 from 1998 to 2003 , increased by 0.01528 from 2003 to 2008 , increased by 0.00461 from 2008 to 2013 , decreased by 0.02203 from 2013 to 2018 , among which the change range from 1998 to 2003 was the largest, which was the growth stage of total shoreline length, natural shoreline and artificial shoreline, It means that the amount of beach sediment deposition and the degree of artificial intervention have increased in this stage.

\subsection{Extraction results and analysis of coastal land use}

4.3.1.Land use analysis of coastal zone. The land use of the coastal zone in 1993, 1998, 2003, 2008, 2013 and 2018 is extracted by using the extraction method described in 4.1, as shown in Figure 2 (taking 1993 as an example only).

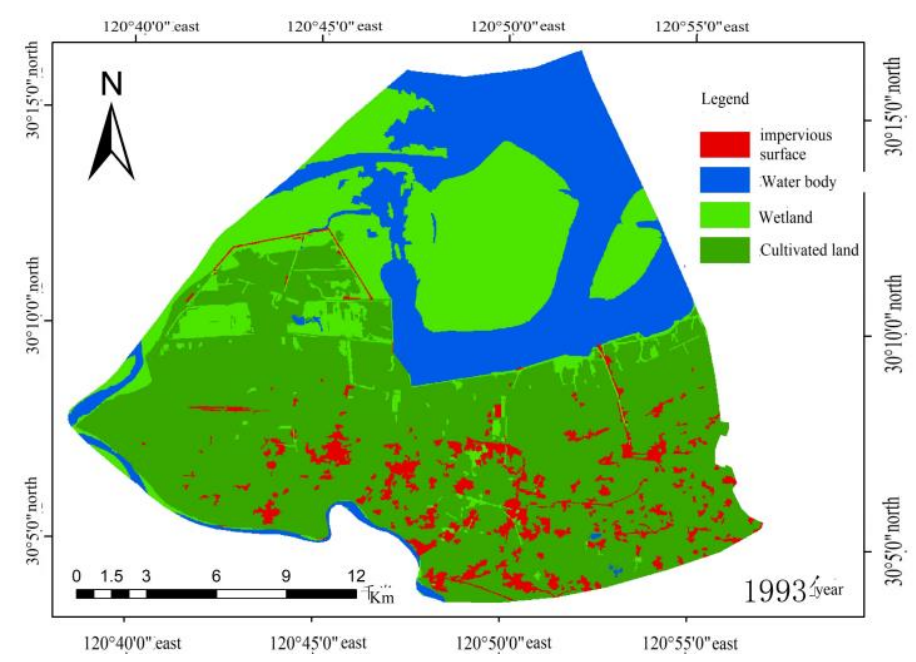

Figure 2 land use map of coastal zone in study area(1993)

The area and proportion of land use types in the study area for many years were obtained by calculating the extracted results. It can be found that cultivated land is the main land type in the study area, accounting for more than $40 \%$ of the total area over the years, with the highest proportion of $49.72 \%$ in 1993. The total change of cultivated land shows a downward trend. From 1993 to 2018, the cultivated land area decreased by $7.81 \%$, with a total of $34.2976 \mathrm{~km}^{2}$, From 2013 to 2018 , the cultivated land area decreased the most, by $5.07 \%$, a total of $22.2636 \mathrm{~km}^{2}$, Only in 2008-2013, there was a brief increase.

The fastest growth rate is the impervious surface, from $5.2 \%$ in 1993 to $23.33 \%$ in 2018 , with a total increase of $79.6522 \mathrm{~km}^{2}$, The period from 2003 to 2008 is the period with the most growth, with a total increase of $30.2267 \mathrm{~km}^{2}$, The slowest growth stage is 2008-2013, which is also a short-term increase stage of cultivated land. It can be found that there is a certain inverse correlation between impervious surface and cultivated land.

Wetlands in the study area, including coastal beach and inland wetlands, lost $8.23 \%$ of the total area from 1993 to 2018, a total of $36.1314 \mathrm{~km}^{2}$, There was only a small increase from 1998 to 2003, and the rest of the time showed a decrease. The most decrease stage was from 2003 to 2008 , with a decrease of $5.66 \%$, a total of $5.65 \mathrm{~km}^{2}$ 。

Wetlands in the study area, including coastal beach and inland wetlands, lost $8.23 \%$ of the total area from 1993 to 2018 , a total of $36.1314 \mathrm{~km}^{2}$, There was only a small increase from 1998 to 2003, and the rest of the time showed a decrease. The most decrease stage was from 2003 to 2008 , with a decrease of $5.66 \%$, a total of $5.65 \mathrm{~km}^{2}$ 。

The proportion of water body kept a stable trend with small fluctuation, and decreased by $21 \%$ in 25 years, with a total of $9.2322 \mathrm{~km}^{2}$, The most decreasing stage was from 2008 to 2013, while the water area increased to varying degrees in 2003-2008 and 2013-2018, which were $2.13 \%$ and $0.53 \%$ respectively. The reason for the increase in the previous stage was mainly due to the reduction of sediment deposition and the reduction of wetland (shoal) area after the completion of coastal dike and Cao'e River sluice, which was replaced by sea area.

On the whole, the degree of artificial development of the whole study area is gradually increasing, which is reflected in the substantial reduction of coastal beach area and the substantial increase of impervious surface area. Cultivated land 
also belongs to the human intervention area, although showing a downward trend, it accounts for a large proportion.

\subsubsection{Analysis of distribution changes of different types.(a) Analysis of water distribution change}

The water bodies in this study include sea water and inland water. However, before the completion of Cao'e River sluice, there was no obvious boundary between sea water and inland water. Therefore, in order to maintain the same time scale, sea water and inland water were not distinguished. The water distribution changes over the years are shown in Figure 3 (taking 1993-2018 as an example). In the figure, the "increase" represents that the non water area of the former phase becomes the water area of the latter phase, "decrease" represents that the water area of the former phase becomes the non water area of the latter phase, "no change" represents that both of the two phases are water area. From the spatial distribution area, it can be clearly found that from 2003 to 2008 , due to the construction of Cao'e River sluice, there were reduced areas with regular shape in the water area on the west side of the study area. From 2008 to 2013, affected by the opening of Changtai expressway, there were reduced areas with strip shape in the sea area.

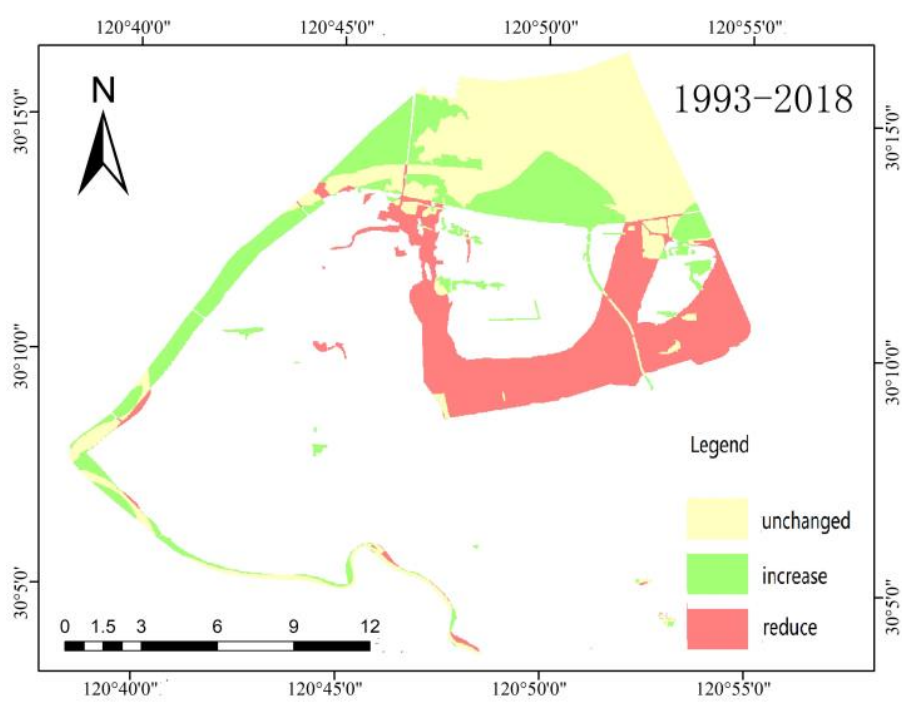

Figure 3 variation of water distribution (1993-2018)

According to the statistical data of water distribution change area over the years (table 1), it can be found that the water distribution change is the most dramatic from 1993 to 1998, the spatial change is the smallest from 2013 to 2018, and the stable area is the largest. From 1993 to 2018, the area of water changed into other features was

\begin{tabular}{lccc}
\hline Data & increase $\left(\mathrm{km}^{2}\right)$ & reduce $\left(\mathrm{km}^{2}\right)$ & stable $\left(\mathrm{km}^{2}\right)$ \\
\hline $1993-1998$ & 31.0608 & 32.0517 & 63.4464 \\
$1998-2003$ & 22.2003 & 28.5651 & 65.9421 \\
$2003-2008$ & 25.2585 & 15.8811 & 72.2613 \\
$2008-2013$ & 5.1658 & 18.7489 & 78.7709 \\
$2013-2018$ & 6.5592 & 4.2300 & 79.7067 \\
\hline
\end{tabular}

(b) Analysis of wetland distribution change The wetlands in this study include coastal tidal flats and inland salt fields. The wetland is the largest land type in the study area, and mainly refers to coastal tidal flats. From figure 3, it can be seen that from 1993 to 2018, the coastal tidal flats located in the northern coast of the study area disappeared in a large area, while the increased area is mainly located in inland, which belongs to inland salt
$42.2469 \mathrm{~km}^{2}$, However, the area from other surface features to water body is $33.0147 \mathrm{~km}^{2}$, The area of stable water body is $53.2512 \mathrm{~km}^{2}$, The change degree of water body distribution was $58.56 \%$, with the reverse change of $32.87 \%$ and the positive change of $25.69 \%$.

fields; During 1993-1998, 1998-2003 and 2003-2008, the northern coastal shoals gradually disappeared. From 2008 to 2018, it can be found that the northern sea area has become stable, and there is no coastal shoals. The inland and sea areas have obvious boundaries due to the construction of coastal dikes; The wetlands located in the Caoejiang River region are mainly affected by sediment deposition, resulting in a small amount of 
short-term wetland area changes in some years. However, since 2013, the image shows that there is no sediment deposition in the Caoejiang River region.

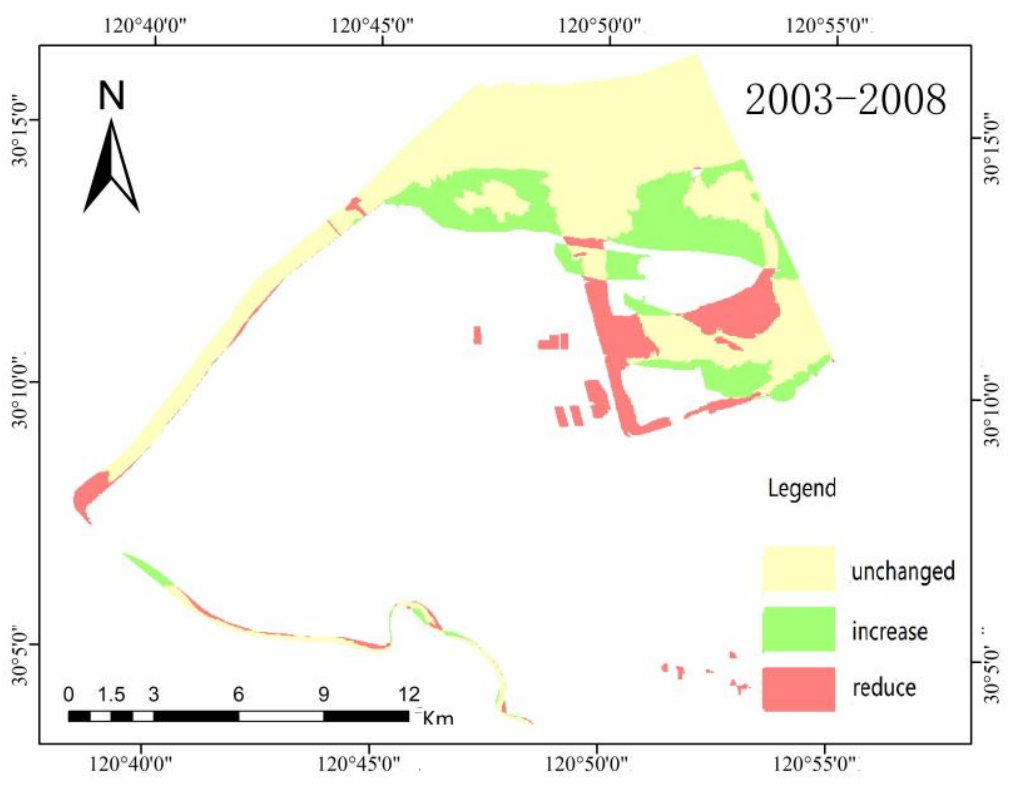

Figure 4 wetland distribution (2003-2008)

According to the statistical data of wetland distribution change area over the years (table 2), it can be found that from 1993 to 1998, the distribution change of wetland was the most dramatic, the total area of increase and decrease was the largest, but the stable area was also the largest. It can be seen from the side that the wetland area in this period was generally larger, while the spatial change from 2013 to 2018 was the smallest, and the stable area was the largest, It accounted for $65.02 \%$ of the total wetland area in this period, indicating that the distribution of wetlands changed relatively little. From 1993 to 2018 , the area of wetland changed into other features was $80.5239 \mathrm{~km}^{2}$, The area from other features to wetland is $44.3925 \mathrm{~km}^{2}$, The area of wetland is $21.9825 \mathrm{~km}^{2}$, The change degree of wetland distribution was $85.04 \%$, mainly in reverse, $54.82 \%$ in reverse and $30.22 \%$ in positive.

Table 2 statistical table of distribution change area of coastal wetland

\begin{tabular}{cccc}
\hline Data & increase $\left(\mathrm{km}^{2}\right)$ & reduce $\left(\mathrm{km}^{2}\right)$ & stable $\left(\mathrm{km}^{2}\right)$ \\
\hline $1993-1998$ & 36.3393 & 46.2096 & 56.3454 \\
$1998-2003$ & 38.0394 & 37.1871 & 55.1655 \\
$2003-2008$ & 26.6025 & 51.4557 & 42.0165 \\
$2008-2013$ & 29.4022 & 33.5677 & 34.6319 \\
$2013-2018$ & 14.8221 & 12.9168 & 51.5529 \\
\hline
\end{tabular}

(c) Analysis on the change of cultivated land distribution

Cultivated land is the main feature type in the study area. Compared with other land use types, cultivated land accounts for a large proportion and is widely distributed. From the change of distribution map, it can be found that the cultivated land in the south of the study area is stable and reduced, mainly due to the expansion of cities and towns. The construction of cultivated land is called impermeable surface such as buildings, while in the north of the study area, a large amount of cultivated land is increased, Gathered in the administrative area of Gaibei Town, it can be seen that due to human intervention, the reclamation of northern coastal tidal flats has changed the land use type from wetland to cultivated land.
Cultivated land is the main feature type in the study area. Compared with other land use types, cultivated land accounts for a large proportion and is widely distributed. From the change of distribution map, it can be found that the cultivated land in the south of the study area is stable and reduced, mainly due to the expansion of cities and towns. The construction of cultivated land is called impermeable surface such as buildings, while in the north of the study area, a large amount of cultivated land is increased, Gathered in the administrative area of Gaibei Town, it can be seen that due to human intervention, the reclamation of northern coastal tidal flats has changed the land use type from wetland to cultivated land. 


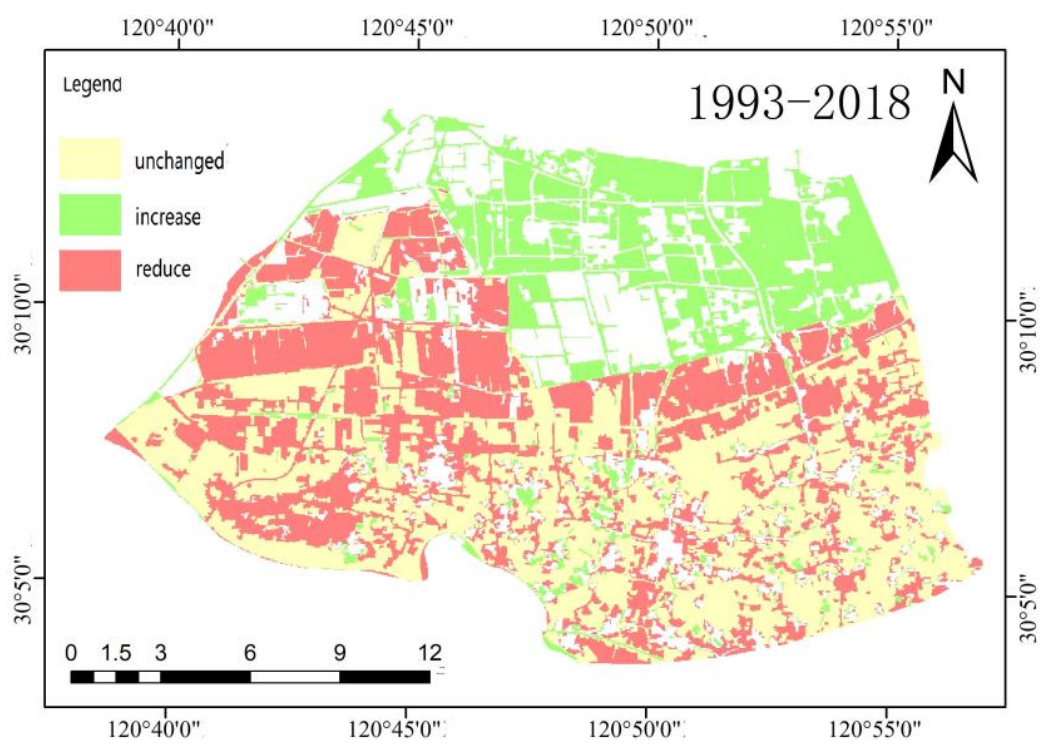

Figure 5 change of cultivated land distribution(1993-2018)

According to the statistical data of cultivated land distribution change area over the years (table 3 ), it can be found that the distribution change of wetland was the most dramatic from 2008 to 2013, the total increase and decrease area was the largest, and the stable area was the smallest, while the spatial change from 1993 to 1998 was the smallest, and the stable area was the largest, accounting for $79.88 \%$ of the total cultivated land in this period, It shows that the change degree of cultivated land distribution in this period is relatively small. From

Table 3 statistical table of cultivated land distribution change area in coastal zone

\begin{tabular}{lccl}
\hline Data & increase $\left(\mathrm{km}^{2}\right)$ & reduce $\left(\mathrm{km}^{2}\right)$ & stable $\left(\mathrm{km}^{2}\right)$ \\
\hline $1993-1998$ & 20.9646 & 27.1836 & 191.1978 \\
$1998-2003$ & 28.6290 & 35.4996 & 176.6628 \\
$2003-2008$ & 33.3873 & 48.1383 & 157.1535 \\
$2008-2013$ & 65.1717 & 49.3650 & 141.1758 \\
$2013-2018$ & 31.1636 & 53.4273 & 152.9201 \\
\hline
\end{tabular}

(d) Analysis on the change of impervious surface distribution

Impervious surface mainly refers to houses, roads, dams, embankments and other artificial buildings, which is the fastest expanding type of surface features in the study area. From the distribution change map (1993-2018 as an example, Figure 6), it can be found that the change
1993 to 2018 , the area of cultivated land changed into other features was $80.5239 \mathrm{~km}^{2}$, The area from other land features to cultivated land is $65.7684 \mathrm{~km}^{2}$, The area of cultivated land changing into other land features is $100.0660 \mathrm{~km}^{2}$, The area of cultivated land is $118.3154 \mathrm{~km}^{2}$, The change degree of cultivated land distribution was $58.36 \%$, mainly in reverse change, $35.22 \%$ in reverse change and $23.15 \%$ in positive change.

of impervious surface corresponds to the change of cultivated land distribution, especially in the Southern region of the study area, the impervious surface shows a continuous expansion trend. The impervious surface mainly shows the human activities in the study area, which can be found by combining with the statistical data of change area in table 4. 


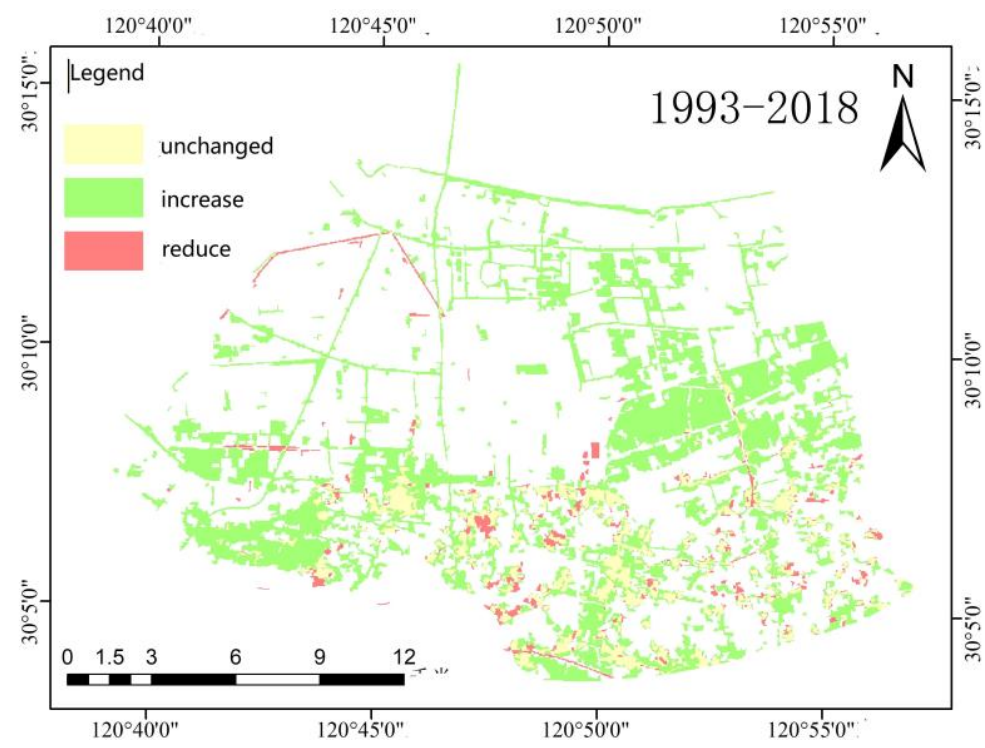

Figure 6 variation of impervious surface distribution(1993-2018)

Table 4 statistical table of distribution change area of impervious surface in coastal zone

\begin{tabular}{lrrc}
\hline Data & increase $\left(\mathrm{km}^{2}\right)$ & reduce $\left(\mathrm{km}^{2}\right)$ & stable $\left(\mathrm{km}^{2}\right)$ \\
\hline $1993-1998$ & 24.2730 & 7.1955 & 15.642 \\
$1998-2003$ & 26.0460 & 13.6602 & 26.2548 \\
$2003-2008$ & 46.8816 & 16.6549 & 35.6459 \\
$2008-2013$ & 34.6809 & 32.7488 & 49.7788 \\
$2013-2018$ & 41.0739 & 23.0438 & 61.4158 \\
\hline
\end{tabular}

According to the statistical data of impervious distribution change area over the years (table 4), it can be found that the distribution change area of impervious surface is the largest from 2003 to 2008, and the spatial change is the smallest from 1993 to 1998. However, due to less human intervention in this period, the impervious surface accounts for less area of the total study area, so the increase and decrease of impervious surface accounts for more area of impervious surface, 8\%. From 2013 to 2018, the stable area is the largest, because the development of the whole study area in this practice period is greatly affected by human factors, and the impervious surface accounts for a large proportion of the total. The stable area accounts for $48.92 \%$ of the total impervious surface area in this period, indicating that the development of this period is still continuing and has a certain foundation. From 1993 to 2018, the area of impervious surface changed into other features is $6.2109 \mathrm{~km}^{2}$, The area from other surface features to impervious surface is $85.8631 \mathrm{~km}^{2}$, It is nearly 14 times of the former, and the area of cultivated land is $16.6266 \mathrm{~km}^{2}$, The change degree of impervious surface distribution is $84.70 \%$, with positive change of $78.99 \%$ and reverse change of $5.71 \%$.

\section{Conclusion}

In this study, the coastal zone of Shangyu Economic Development Zone on the South Bank of Hangzhou Bay is taken as the research area. With the support of remote sensing and geographic information technology, the research area is divided into water area and land area. From the changes of coastal water line and land use classification of coastal zone, the changes of coastal zone over the years are analyzed, and its ecological health status is scientifically evaluated, The comprehensive management and protection measures are proposed.

The main conclusions are as follows:

(a) In this study, we extracted the coastline of Shangyu Economic Development Zone on the South Bank of Hangzhou Bay over the years, and found that the change was obvious, mainly as follows: the total coastline length decreased to the main trend, only 1998-2003 was the rising period, which coincided with the rising period of the natural coastline, and $66.67 \%$ of the coastline disappeared from 1993-2018, The main reason for the decline of the total shoreline length is the reclamation and development of the beach under the coastal planning, which makes the original natural form of the curved shoreline into a regular boundary. The fractal dimension index is used to characterize the natural condition of coastline. In 1998, the highest 
proportion of natural coastline is 1.03973 , while in 2018 , the lowest proportion of natural coastline is 1.0111. The change range from 1998 to 2003 is the largest, which is the growth stage of total coastline length, natural coastline and artificial coastline, It means that the amount of beach sediment deposition and the degree of artificial intervention have increased in this stage.

(b) Based on the classification of land use in the coastal zone of the study area, it is found that cultivated land is the main land type in the study area, and the impervious surface is the fastest growing. The degree of artificial development in the whole study area is gradually increasing, and the area of coastal beach is greatly reduced, and the area of impervious surface is greatly increased. From the analysis of the changes of different types of surface features, wetland and impervious surface are the two most dramatic changes in the study period. Wetland is mainly transformed into other surface features, and impervious surface is mainly transformed into other surface features.

Fund Project: Science and technology project of Zhejiang Provincial Department of water resources in 2020 "Research on the environmental impact of the development of the South Bank of Hangzhou Bay on the coastal zone based on remote sensing data", project number: RC2066.

\section{Reference}

[1] Zhao Yi, Wu Yanming, sun Zhongwei. Landscape ecological characteristics and management of coastal zone [J]. Journal of Applied Ecology, 1990,1 (04): 373-377.

[2] $\mathrm{Xu}$ Yan, $\mathrm{Pu}$ Lijie, Zhang Runsen, et al. Spatiotemporal dynamics of land use / cover change in coastal zone of Jiangsu Province in recent years $[\mathrm{J}]$. Resources and environment of Yangtze River Basin, 2012,21 (05): 565-571.

[3] Li Wei, Li Yuanyuan, Tian Yan, et al. Study on PLSR salt model of coastal beach based on envelope method [J]. Progress of marine science, 2014,32 (04): 501-507.

[4] He Xiaofang, Chen Yan, Zhu Min, et al. Spatiotemporal change of vegetation coverage and its response to land use change in Yancheng coastal zone [J]. Journal of Central South University of forestry science and technology, 2016,36 (02): 101-105.

[5] Max Rudolf Muskananfola, Supriharyono, Sigit Febrianto. Spatio-temporal analysis of shoreline change along the coast of Sayung Demak, Indonesia using Digital Shoreline Analysis System[J]. Regional Studies in
Marine Science,2020,34. 